\title{
The Development of Patient Scheduling Groups for an Effec- tive Appointment System
}

Yu Li Huang ${ }^{1}$

${ }^{1}$ Mayo Clinic, Rochester, Minnesota, USA

\section{Keywords}

Appointment scheduling, scheduling group, scheduling efficiency, scheduling flexibility

\section{Summary}

Background: Patient access to care and long wait times has been identified as major problems in outpatient delivery systems. These aspects impact medical staff productivity, service quality, clinic efficiency, and health-care cost.

Objectives: This study proposed to redesign existing patient types into scheduling groups so that the total cost of clinic flow and scheduling flexibility was minimized. The optimal scheduling group aimed to improve clinic efficiency and accessibility.

Methods: The proposed approach used the simulation optimization technique and was demonstrated in a Primary Care physician clinic. Patient type included, emergency/urgent care (ER/UC), follow-up (FU), new patient (NP), office visit (OV), physical exam (PE), and well child care (WCC). One scheduling group was designed for this physician. The approach steps were to collect physician treatment time data for each patient type, form the possible scheduling groups, simulate daily clinic flow and patient appointment requests, calculate costs of clinic flow as well as appointment flexibility, and find the scheduling group that minimized the total cost.

Results: The cost of clinic flow was minimized at the scheduling group of four, an $8.3 \%$ reduction from the group of one. The four groups were: 1. WCC, 2. OV, 3. FU and ER/UC, and 4. PE and NP. The cost of flexibility was always minimized at the group of one. The total cost was minimized at the group of two. WCC was considered separate and the others were grouped together. The total cost reduction was $1.3 \%$ from the group of one.

Conclusions: This study provided an alternative method of redesigning patient scheduling groups to address the impact on both clinic flow and appointment accessibility. Balance between them ensured the feasibility to the recognized issues of patient service and access to care. The robustness of the proposed method on the changes of clinic conditions was also discussed.

Correspondence to:

Yu Li Huang, Ph.D.

Mayo Clinic

200 First Street SW, Rochester, MN 55905

Email: huang.yuli@mayo.edu
Appl Clin Inform 2016; 7: 43-58

http://dx.doi.org/10.4338/ACl-2015-08-RA-0097

received: August 14, 2015

accepted: November 29, 2015

published: January 27, 2016

Citation: Huang YL. The development of patient scheduling groups for an effectiveappointment system. Appl Clin Inform 2016; 7: 43-58

http://dx.doi.org/10.4338/ACl-2015-08-RA-0097 


\section{Background}

Patient access to care [1-3] and long wait time [4-6] has been identified as major problems in outpatient delivery systems. The impacts included medical staff productivity and stress $[7,8]$, service quality and efficiency [9], as well as health-care cost [10,11]. There have been many efforts in developing the best way to schedule patient appointments in outpatient settings. The primary goal was to improve patient experience and to reduce clinic cost by streamlining the clinic flow so that a clinic could function more effectively. Typical scheduling methods focused on allocating patient appointment slots by developing appointment rules to minimize patient wait time $[5,8,12-16]$ or the cost of clinic flow [17-22]. Some methods studied the impact of patient no-shows to develop a better way of overbooking patient appointments to increase schedule availability [2, 14, 23-27]. Other methods focused on the sequence of how different patient types were scheduled in a clinic day to generate better clinic flow [28-29]. A study developed a cost-effective algorithm to determine the size of the appointment slot for patients who required the least amount of treatment time [30]. These efforts improved clinic capability and service quality significantly. However, due to the high variability of physician treatment time in a scheduled patient type, most solutions were limited for further improvement. The majority of clinics used the common patient types such as new patients (NP) or follow-up patients (FU) for scheduling. Depending on specialty, other patient types could also be created such as physical exam (PE) for a Primary Care or post-operation visit (PO) for an Orthopedic Surgery clinic. In order to capture the treatment time variation within each patient type, researchers developed algorithms to classify patient types into appointment types based on the length of treatment time required [31-32]. The length of treatment time could be determined based on patient demographic information and conditions [33-34] or minimizing the cost of clinic flow [31]. These studies demonstrated further improvement could be achieved. However, the new appointment types might not be medically intuitive and would require additional training of schedulers. The proposed study provided an alternative method to reform existing patient types into scheduling groups to improve service efficiency and patient access to care.

\section{Objectives}

To avoid additional training that could delay patient treatment while still being able to capture the treatment time variation within an appointment type, the proposed study investigated how the existing patient types could be grouped into appointment or scheduling groups. This was done using simulation optimization approach to trial possible grouping scenarios. The objective was to minimize the total cost of clinic flow and scheduling flexibility. The study method was demonstrated in a Primary Care facility.

\section{Methods}

This study proposed to determine the most appropriate patient scheduling groups that can accommodate patients' request for appointments and still generate a good clinic flow. Clinic flow was defined by patient visit starting from patient check-in to check-out. The process generally involved patients waited in waiting room, called by nurses for visit information, taken to exam room, waited for the physician, consulted with the physician, and completed the visit. A few key metrics usually captured by the clinic flow were patient wait time, physician idle time, and overtime. A scheduling group was defined as various patient visit types to be scheduled in an appointment slot length. For example, a 15-minute scheduling group could be used to schedule office visit or follow-up patients.

The proposed approach used the simulation optimization technique and was demonstrated in a real-life data collected from a Primary Care physician. Simulation optimization was used to find the best input variable values from all possibilities that optimized an objective function without explicitly assessing each possibility [35]. The approach included collected physician treatment time data for each patient type, formed the possible scheduling groups, built simulation model that represented daily clinic flow to obtain patient wait time, physician idle time and overtime, simulated pa- 
tient appointment requests based on the appointment distribution for each patient type to obtain the deficit between appointment requests and availability, run trials for each possible scheduling group in both simulation models, calculated the total cost from clinic flow and appointment flexibility for each scheduling group, realized the most appropriate scheduling group that minimized the total cost. An overarching figure ( $>$ Figure 1 ) was provided to demonstrate the steps and their aims. Appointment flexibility was defined to identify how the scheduling groups met the demand of appointment requests.

\subsection{Data Collection}

There were four medical providers in this Primary Care clinic, and one physician participated in the study. This Primary Care clinic is a rural clinic and a satellite location for a large health system. The clinic schedules six different patient types: emergency/urgent care (ER/UC), follow-up patient (FU), new patient (NP), office visit (OV), physical exam (PE), and well child care (WCC). The patient appointments begin at 8:00 am and 1:00 pm. The desired clinic finish time is 5:00 pm. The data collection primarily focused on the time of patient visit with the physician. The manual data collection was recorded by the physician at the time he or/she entered or exited the exam room. Data was collected for one month. Results are summarized in $>$ Table 1 . Table 1 provided physician treatment time including average (Avg.), standard deviation (SD), 95\% confidence interval (CI), and the number of patients with distribution percentage for each patient type. The study data also indicated a current average patient no-show rate of $10.4 \%$ on average and the physician needed roughly four minutes for preparation and charting for each patient. These four minutes were added into the faceto-face time to be the actual treatment time needed to complete a patient.

\subsection{Possible Scheduling Groups}

The possible scheduling groups ( $\triangleright$ Table 2 ) were generated from the six patient types based on the length of treatment time. The maximum number of scheduling groups was six and the minimum was one. To be noted, the participating physician used one scheduling group for all six patient types. The Primary Care clinic considered this to be the most flexible appointment template. When combining the current patient types, they were sorted by their average treatment time plus four minutes additional time in an increasing order: WCC (17.8 minutes), OV (20.2 minutes), FU (22.0 minutes), ER/UC (22.7 minutes), PE (24.5 minutes), and NP (29.0 minutes). To simplify the current patient type abbreviation, let $a$ be WCC, $b$ be OV, $c$ be FU, $d$ be ER/UC, $e$ be PE, and $f$ be NP group where $a$ $<b<c<d<e<f$ based on their average treatment time. The possible scheduling groups are presented in Table 2 . For group count of 6 , each patient type was its own scheduling group. For group count of 2 and 5, there were five possible scenarios. For group count of 3 and 4 , there were ten possible scenarios. For group count of 1 , all patient types were considered all together as one scheduling group. For example, group count of 5 was ordered by the length of their treatment time, the first possible scenario (5_1) would be $\{a b, c, d, e, f\}$ where $a$ and $b$ were grouped together and the rest was by itself. The second possible scenario (5_2) was $\{a, b c, d, e, f\}$. The third scenario (5_3) was $\{a, b, c d, e$, $f\}$. The forth scenario (5_4) was $\{a, b, c, d e, f\}$. Finally, the last scenario (5_5) was $\{a, b, c, d, e f\}$. $\checkmark$ Table 2 also provided the weighted average treatment based on distribution percentage when combining groups. For example, for scenario 5_1, the group was formed as: $\{a b, c, d, e, f\}$. By combing group $a$ and $b$, the average treatment time was $(17.8 \times 6.8 \%+20.2 \times 55.7 \%) /(6.8 \%+55.7 \%)=$ 19.9 minutes. Therefore, the average treatment times are 19.9 minutes for group $a b, 22.0$ minutes for group $c, 22.7$ minutes for group $d, 24.5$ minutes for group $e$, and 29.0 minutes for group $f$.

\subsection{Simulation Optimization Modeling}

To measure the effectiveness of these scheduling groups from $>$ Table 2 on the clinic flow, the basic clinic flow was simulated. The simulation was modeled using a Microsoft Excel macro function applied to the participating physician's daily clinic schedule. An example simulator for group count of 6 was created as an on-line supplemental material. This physician had a 22-patient appointment template (11 patients in the morning and 11 in the afternoon). Morning section started at 8:00 am 
and afternoon section started at 1:00 pm with an hour lunch break. Each slot was scheduled at the designated average treatment time from its scheduling group. Based on the distribution percentage from $>$ Table 1, a 22-patient template contented of 2 WCCs, 12 OVs, 3 FUs, 1 ER/UC, 2 PEs, and 2 NPs. These patient slots were distributed evenly throughout a clinic day; shown in $>$ Table 3 .

Additional assumptions in the model were that

1. all patients arrived on time;

2. inter-appointment time (e.g, time spent on non-clinical activities) was not considered; and

3. the physician started on time.

Variation in the actual length of treatment time for each patient scheduling group was modeled by the Gamma distribution $[2,8,36]$ seeded with a random number generator, with the mean and the standard deviation from $>$ Table 1 . A no-show rate of $10.4 \%$ was incorporated. The simulated clinic flow model provided the information regarding patient wait time $(W)$, physician idle time $(P)$, and overtime $(O)$. Let the cost of patient wait time be $c_{w}$ the cost of physician idle time be $c_{p}$, and the cost of overtime be $c_{o}$, thus the expected total cost on clinic flow $\left(T_{\text {flow }}\right)$ was $T_{\text {flow }}=c_{w} W+c_{p} P+c_{o} O$. The cost ratios between physician idle time and patient wait time were reported to range widely (e.g., 1 to 100) depending on the specialty [37]. In this Primary Care case, the chosen cost ratio was 5, which was expected to be reasonable for a Primary Care clinic [38]. Hence, the assumptions were $\$ 10$ per hour for the cost of patient wait time $c_{w} \$ 50$ per hour for physician idle time $c_{p}$, and 1.5 times of physician idle time or $\$ 75$ per hour for overtime $c_{o}$.

To measure the flexibility, the random appointment requests were generated based on the distribution percentage in Table 1 . Given a 22-patient schedule, the measurement was to compare the first 22 appointment requests to appointment availability in a clinic day and calculate the total appointment length of the underage slots. For example, a clinic day designed for six scheduling groups with 2 WCCs, 12 OVs, 3 FUs, one ER/UC, 2 PEs, and 2 NPs, if the first 22 requests were 4 WCCs, 10 OVs, 2 FUs, 2 ER/UCs, one PE, 3 NPs, the underage slots were 2 WCCs, one ER/UC, and one NP. The total appointment length of the underage slots was $87.3(17.8 \times 2+22.7+29)$ minutes. Generally, the schedule with only one scheduling group would have the most flexibility. On the other hand, the schedule with all six scheduling groups would have the least flexibility. The underage represented the lost opportunity for patients to obtain appointments. Let the total length of the underage slots be $U$ and the cost of this underage be $c_{u}$. The cost on flexibility $\left(T_{f l e x}\right)$ was calculated by $T_{f l e x}=c_{u} U$. The cost of underage $c_{u}$ was assumed to be equal to the cost of patient wait time $c_{w}$ since it represented the lost opportunity for a patient to be seen during the length of time in that underage slot. To be noted, in reality, a clinic could schedule a patient in a non-designated slot, which would potentially increase the cost of clinic flow. Each scheduling group and its treatment time from Table 2 were input into the simulation model with 100 replications each. Each replication represented a possible clinical day. Combining both cost of clinic flow and flexibility, the total cost $\left(T_{\text {total }}\right)$ is defined as $T_{\text {total }}$. Then, the most appropriate scheduling groups were selected where $T_{\text {total }}$ is minimized.

\section{Results}

In theory, a schedule with more scheduling groups generated a clinic flow with less waiting and overtime since the treatment time variations were captured by the scheduled appointment slots. However, too many scheduling groups reduced the opportunities for patients to obtain the designated appointments. The simulation results from clinic flow were shown in $>$ Figure 2 . $>$ Figure 2 (a) indicated that the average wait time was minimized at the scheduling group of 3_7, which reduced by $8.9 \%$ (9.4 to 8.5 minutes) from the scheduling group of one. The average physician idle time had a slightly decreasing trend and was minimized at the group of 4_9; see $>$ Figure 2(b). The reduction was $8.7 \%$ (3.2 to 2.9 minutes). The average overtime also had a decreasing trend and was minimized at the group of 4_10; see $>$ Figure 2(c). The reduction was calculated to be $19.3 \%$ (10.9 to 8.8 minutes). The overall clinic flow performance shown in $>$ Figure $2(\mathrm{~d})$ on the expected total cost of patient wait time, physician idle time, and overtime was minimized at the group of $4 \_10$. The reduction was $8.3 \%$ (96.8 to 88.8). The four groups were $\{a, b, c d, e f\}$. 
The performance measurements generated by appointment flexibility were shown in $>$ Figure 3 . -Figure 3(a) indicated that the appointment underage count had an increasing trend as the scheduling groups increased. Besides the all-together scheduling group, the underage count was minimized at the group of 2_5, which generates the least underage cost. The two groups were $\{a b c d e, f\}$. As depicted in Figure 3(b), the case where only one scheduling group was formed was always the most flexible scenario for appointment requests. Therefore, combining both performance measurements, the overall cost of clinic flow and appointment flexibility shown in $>$ Figure 4 was minimized at the group of 2_1, which was reduced by $1.3 \%$ (96.8 to 95.5). The two groups were $\{a, b c d e f\}$. This suggests that for the participating physician the most appropriate patient scheduling group count was two where WCC was by itself and the rests were grouped together.

- Figure 4 also provided the best grouping in each group count. For the group count of two, the most appropriate combination that minimized the total cost was 2_1 where the groups were $\{a$, $b c d e f\}$. For the group count of three, the most cost-effective combination was 3_6 where the groupings were $\{a, b c d, e f\}$. For the group count of four, the best scenario was $4 \_2$. The groupings were $\{a$, $b c d, e, f\}$. Lastly, for the group count of five, the best scenario was $5 \_2$ and the groupings were $\{a, b c$, $d, e, f\}$. These results provided the participating physician grouping options if he/she decided the desired number of groups.

\section{Discussions}

This discussion section aimed to demonstrate the changes on the optimal grouping when clinic conditions varied. The purpose was to provide sensitivity analysis for other clinics to possibly adopt the proposed approach. Three clinic conditions were discussed: cost ratio, no-show rate, and patient type distribution. Three levels for each condition were chosen hypothetically. The discussion was based on a 22-patient schedule (11 in the morning and 11 in the afternoon).

- Relative cost ratio of physician idle and patient wait time at three levels: 5, 10 and 15. Assuming $\$ 10$ an hour for patient wait minute and overtime cost was 1.5 times the physician's idle cost. The different level of the cost ratios represented possible practice differences or was due to practice locations.

- The probability of no-show at three levels: $5.4 \%, 10.4 \%$ and $15.4 \%$ at $5 \%$ increment. The current no-show rate was $10.4 \%$ on average. These three levels represented low, median and high noshow rates.

- Patient type distribution at three different levels. The first level consisted of 2 WCC, 12 OV, 3 FU, $1 \mathrm{ER} / \mathrm{UC}, 2 \mathrm{PE}$, and $2 \mathrm{NP}$ slots. This was what currently taken place in the participating physician's clinic. The second level had 2 WCC, 11 OV, 3 FU, 1 ER/UC, 2 PE, and 3 NP slots, which increased a slot for NP and reduced a slot from OV. The third level included 2 WCC, 10 OV, 3 FU, 1 ER/UC, 3 PE, and 3 NP slots, which continuously reduced a slot from OV and increased a slot from PE. The slots were distributed evenly throughout a day. These three different cases represented patient type distributions varied specially from OVs to longer treatment types such as PE and NP; shown in Table 4.

There were a total of 27 combinations of levels. Each combination was simulated on all grouping scenarios with 100 simulation runs. The results, presented in Table 5, concluded the following:

- When cost ratios increased, meaning that the physician idle time was valued at the higher impact to clinic flow, the optimal scheduling group required to capture more precisely on patient treatment time to prevent the physician from idling. For example, given the first distribution and 5.4\% no-show rate, the optimal scheduling group changed from 2_1 to 3_6 from cost ratio of 5 to 10 or 15. At cost ratio 5 for the group 2_1, bcdef was grouped together and scheduled at a mean of 21.9 minutes. The group 3_6 at higher cost ratios separated bcd (20.7 minutes) and ef (27.1 minutes) to capture the treatment time difference. This was to prevent the procedures that required less treatment time to be scheduled at longer treatment time slots such as the highest demand (56\%) procedure $b$, which required 20.2 minutes on average for treatment time by itself. The grouping potentially generated an average of 1.7 minutes $(21.9-20.2)$ on physician idle time per patient for 
group 2_1, but only 0.5 minutes $(20.7$ - 20.2) for group 3_6. Increasing cost ratio reduced physician idle time by $1.2(1.7-0.5)$ minutes on average per patient.

- When no-show rate increased in general, the chances of physician idling increased especially for unscheduled appointment slots that were designed for longer procedure. Hence, the optimal scheduling adjusted the scheduled length to minimize the effect and created more flexibility for scheduling. For example, for the second distribution at cost ratio 5, the optimal scheduling group changed from 2_4 to 2_1 when no-show rate increased from $10.4 \%$ to $15.4 \%$. At no-show rate $10.4 \%, a b c d$ was grouped at 20.5 minutes and ef was grouped at 27.1 minutes. When no-show rate increased to $15.4 \%$, $a$ was grouped separately from $b c d e f$ at 21.9 minutes. Placing ef with $b c d$ shortened the scheduled time of 5.2 minutes on average which led to the potential saving on physician idle time when no-shows for patient type $e$ or $f$ occurred. This also provided the flexibility for $b c d$ patients to be scheduled at ef slots when no-shows occurred. The cost of appointment flexibility reduced by $38 \%$ from 5.89 to 3.68 .

- Given the definition of patient type distribution in this study, changing from 1 to 3, the optimal scheduling accommodated the changes by capturing more precisely on patient treatment time. This minimized the cost of clinic flow and maintained similar scheduling flexibility. For example, from distribution 1 to 3 at no-show rate $15.4 \%$ and cost ratio of 10, the optimal scheduling group changed from 2_1, 3_6, to 3_1. Group 2_1 had $a$ grouped separately from $b c d e f$ at 21.9 minutes. Group 3_6 had $a$ by itself, $b c d$ together at 20.7 minutes, and ef combined at 27.1 minutes. Group 3_1 had abcd grouped at 20.5 minutes, and $e$ and $f$ both separated. From group 2_1 to 3_6, ef was separated from $b c d$ to ensure that the treatment time difference was captured since a NP $(f)$ was added and an OV $(b)$ was removed. Allowing $b c d$ by themselves would prevent physician idle time. From group 3_6 to 3_1, since a PE (e) was added and an OV (b) was removed from distribution 2 to $3, \mathrm{PE}(e)$ treatment time became more influential to clinic flow and needed to be separated from NP $(f)$. In addition, the decision grouped $a$ with $b c d$, which potentially reduced physician idling and improved scheduling flexibility from 8.23 to 7.58 .

The discussion concluded that the optimal scheduling group varied by the changes of cost ratio, noshow rate and patient type distribution ( Table 5 ). In general, when physician idle cost became more influential to the overall costs, the optimal scheduling group adjusted to reduce appointment slot length by grouping longer slots with shorter ones to prevent physician from idling. When appointment flexibility became an issue, the optimal decision would be to combine slots to have less scheduling groups. When clinic flow cost mainly came from congested clinic flow, the optimal scheduling group would tend to separate short treatment time groups from long treatment time groups to capture the treatment time difference. This would prevent the procedures that required less treatment time to be placed at longer time slots, which could generate physician idling. On the other hand, the separation would also prevent longer procedures from being scheduled at the shorter slots, which generated long patient waiting. It is important to note that the study has some limitations due to the nature of computer simulation based on limited data set collected from a single Primary Care physician. Many factors such as different patient population, different types of clinic, and variation of patient profile over time can confound the results.

\section{Conclusions}

This study provided an alternative method of redesigning patient scheduling groups using simulation optimization approach to minimize the impact on both clinic flow and appointment flexibility. This study demonstrated the methods using a real-life example from a Primary Care physician. The study suggested that given the current six patient types this clinic should have two scheduling groups. One group for only well child care appointments set at 18 minutes. Another group for the rest of patient types and should be scheduled for 22 minutes. The cost saving was $1.3 \%$ from the scheduling group of one. This decision clearly indicated that appointment flexibility out-weighted clinic flow since the low cost ratio had shifted the optimal decision to be impacted by appointment flexibility more. As discussed, the decision algorithm adjusted to clinic conditions such as cost ratio, no-show rate, and distribution of different patient types to find the most appropriate scheduling 
groups. For specialty clinics which had higher cost ratio, the clinic flow highly impacted the grouping decision, especially on physician idle time. In the discussed example, the optimal saving on physician idle time was 1.2 minutes per patient. If 22 -patients are seen in a day, the time saved is about 26 minutes. For clinics with a relatively high no-show rate, the grouping decision was to have less scheduling groups, which allowed clinics to schedule patients more freely. The studied case demonstrated a 38\% improvement based on scheduling flexibility. For clinics that have more patients who required longer treatment, the grouping solution was to find the balance between flexibility and clinic flow to reduce the cost. Future research may include actual implement the algorithm systematically, document issues such as schedule conflict for further approach adjustment, and understand the impact on patient service and access to care.

\section{Clinical Relevance Statement}

This study aimed to improve outpatient appointment performance by finding the most appropriate scheduling groups without compromising clinic flow and appointment flexibility. The step-by-step approach discussed used a real-life case from a Primary Care physician. This study can guide clinics to redesign their scheduling group to be more efficient and effective. The discussion further provided the versatility of the optimal grouping decision.

\section{Conflicts of interest statement}

The authors declare that they have no conflicts of interest in the research.

Protection of Human and Animal Subjects

The research study was not human subject research. 


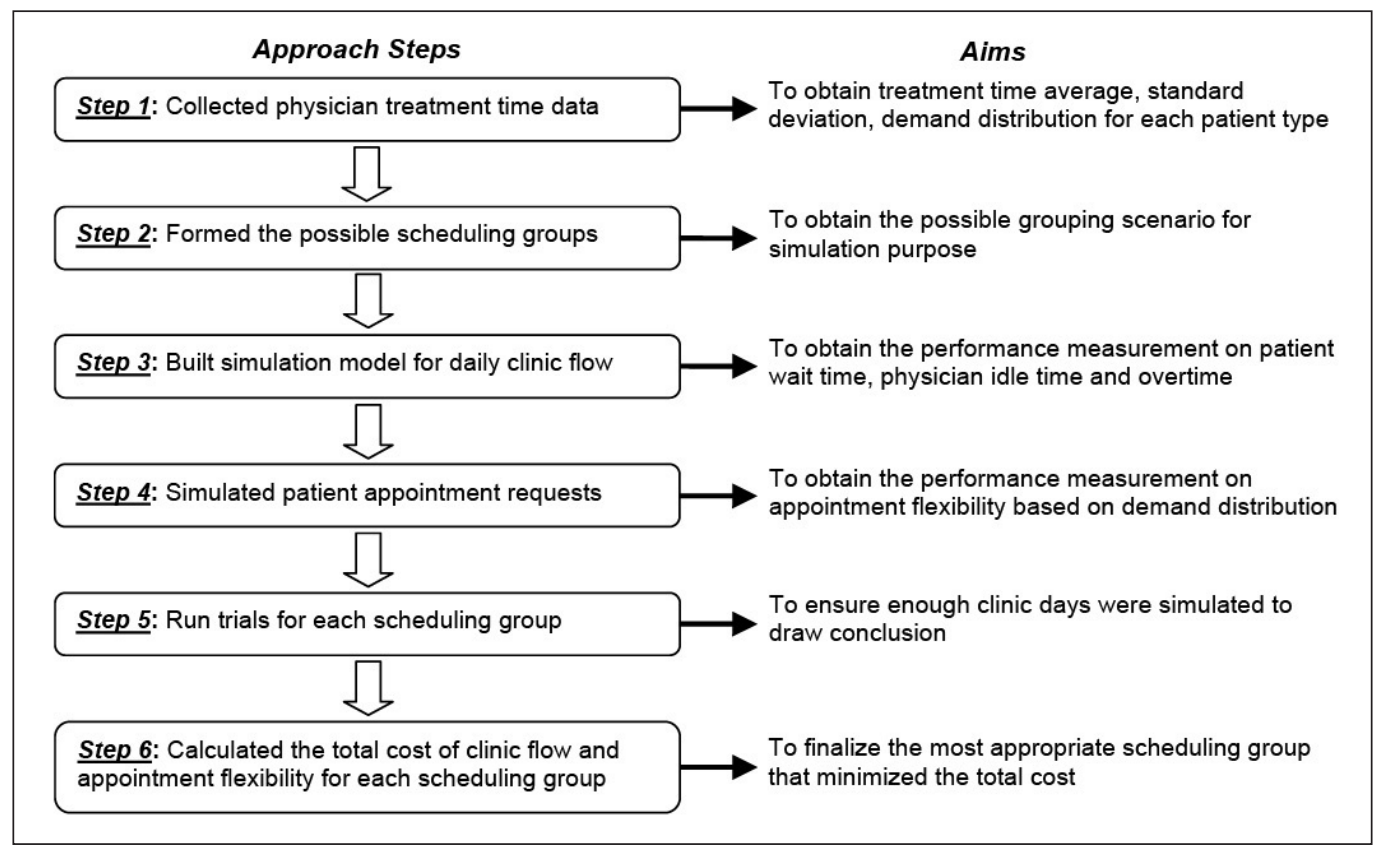

Fig. 1 An overarching figure to demonstrate the approach steps and aims 


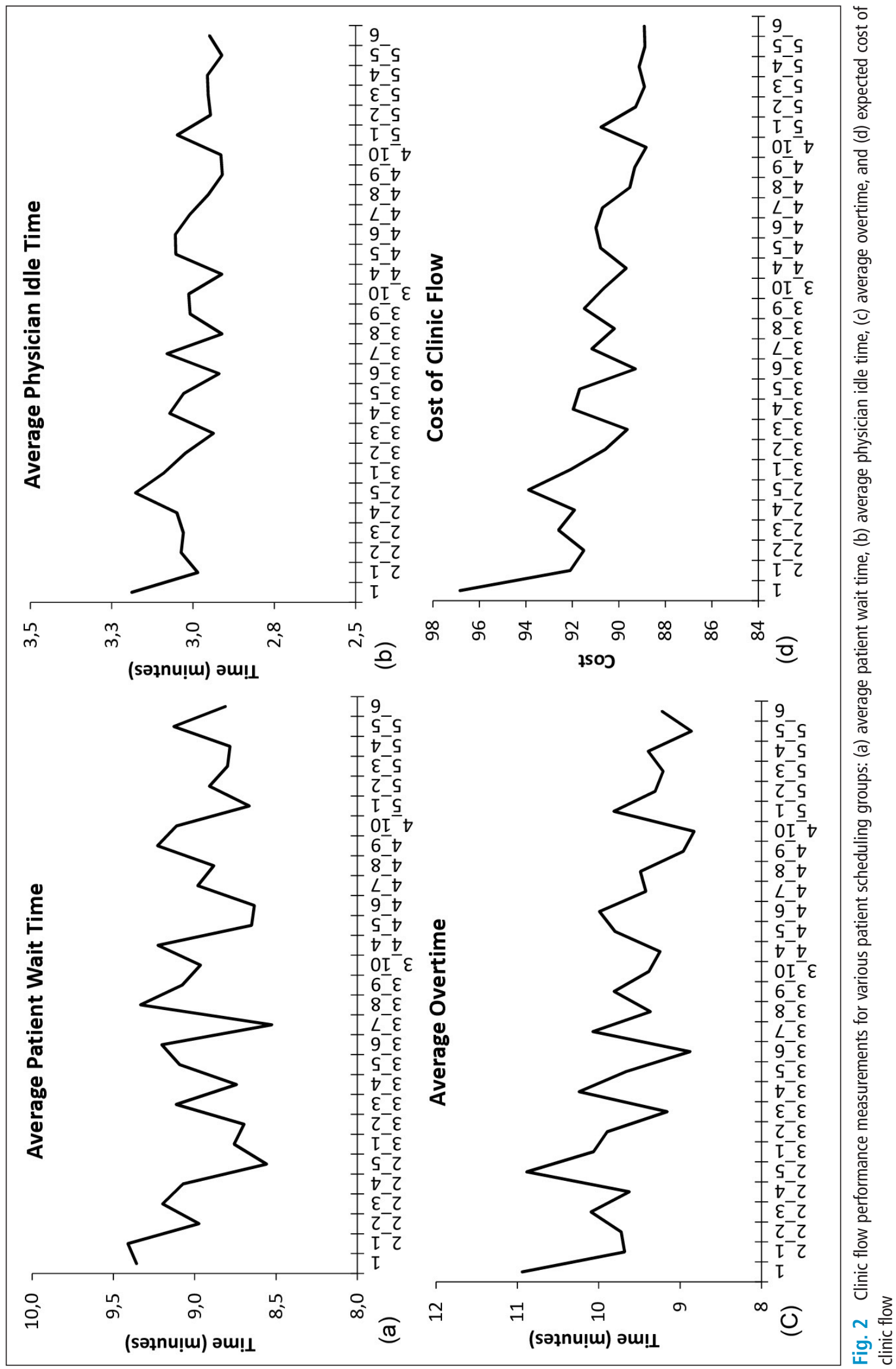




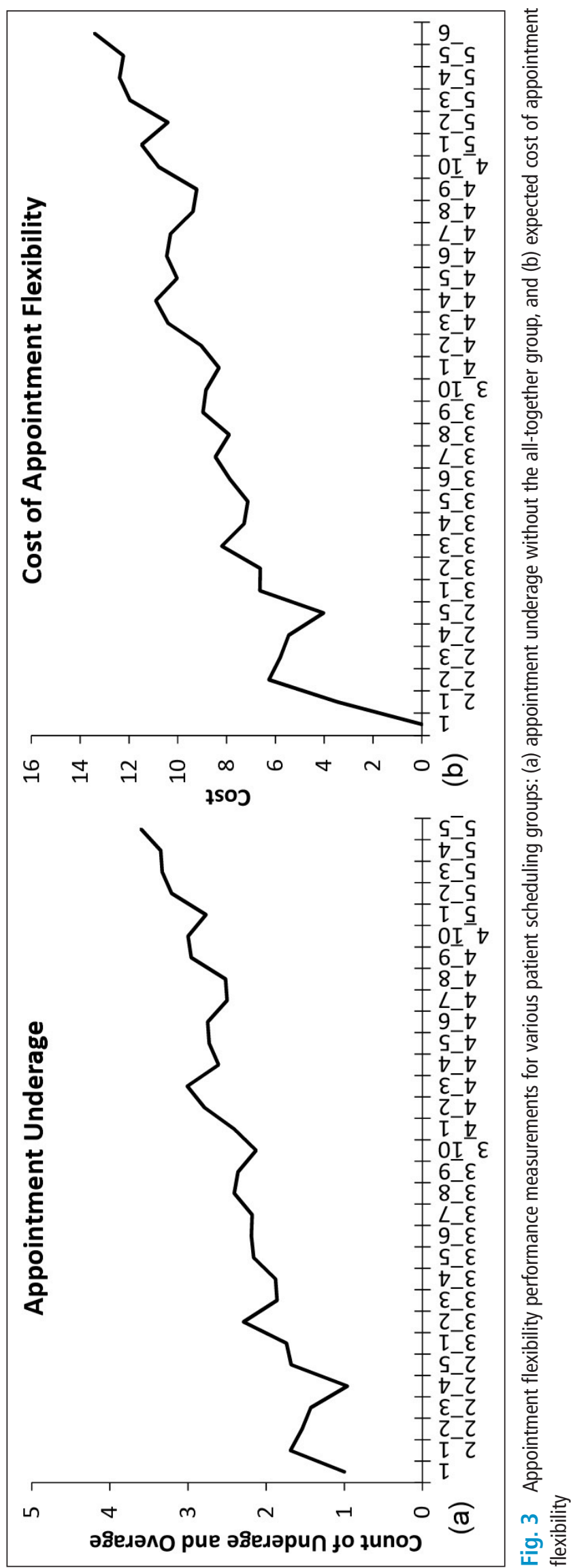




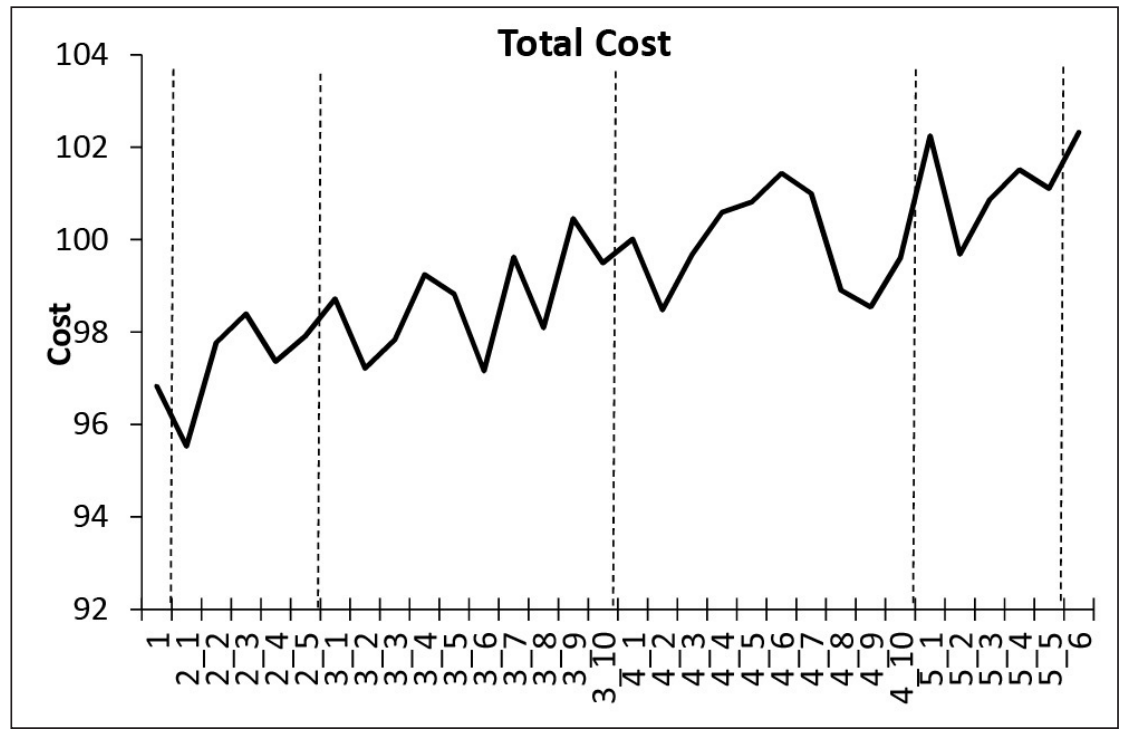

Fig. 4

Total cost of combing clinic flow and appointment flexibility for various scheduling groups (each group count was separated by a dash line) 
Table 1 The Summary of Physician Face-to-Face Treatment Time Data

\begin{tabular}{|c|c|c|c|c|c|}
\hline \multicolumn{6}{|c|}{ Treatment Time } \\
\hline \multirow{2}{*}{$\begin{array}{l}\text { Appointment } \\
\text { Type } \\
\text { WCC }\end{array}$} & \multirow{2}{*}{$\begin{array}{c}\begin{array}{l}\text { Avg. } \\
\text { (minutes) }\end{array} \\
13.8\end{array}$} & \multirow{2}{*}{$\begin{array}{l}\text { SD } \\
\text { (minutes) } \\
\qquad 6.0\end{array}$} & \multirow{2}{*}{$\begin{array}{l}95 \% \mathrm{Cl} \\
(9.5,18.2)\end{array}$} & \multicolumn{2}{|c|}{ Number of Patients (Distribution \%) } \\
\hline & & & & 21 & $(6.8 \%)$ \\
\hline OV & 16.2 & 7.2 & $(14.7,17.7)$ & 171 & $(55.7 \%)$ \\
\hline FU & 18.0 & 12.4 & $(15.0,20.9)$ & 48 & $(15.6 \%)$ \\
\hline ER/UC & 18.7 & 5.2 & $(13.4,23.9)$ & 16 & $(5.2 \%)$ \\
\hline PE & 20.5 & 5.4 & $(16.3,24.7)$ & 22 & $(7.2 \%)$ \\
\hline NP & 25.0 & 8.3 & $(21.2,28.8)$ & 29 & $(9.4 \%)$ \\
\hline Total & 17.5 & 8.4 & & 307 & $(100 \%)$ \\
\hline
\end{tabular}

Table 2 The Possible Scheduling Groups and their Average Treatment Time

\begin{tabular}{|c|c|c|c|}
\hline Group count & Scenario & Group & Average treatment time (minutes) \\
\hline 6 & all separate & $\{a, b, c, d, e, f\}$ & $\{17.8,20.2,22.0,22.7,24.5,29.0\}$ \\
\hline \multirow[t]{5}{*}{5} & 5_1 & $\{a b, c, d, e, f\}$ & $\{19.9,22.0,22.7,24.5,29.0\}$ \\
\hline & 5_2 & $\{a, b c, d, e, f\}$ & $\{17.8,20.6,22.7,24.5,29.0\}$ \\
\hline & 5_3 & $\{a, b, c d, e, f\}$ & $\{17.8,20.2,22.2,24.5,29.0\}$ \\
\hline & $5 \_4$ & $\{a, b, c, d e, f\}$ & $\{17.8,20.2,22.0,23.7,29.0\}$ \\
\hline & 5_5 & $\{a, b, c, d, e f\}$ & $\{17.8,20.2,22.0,22.7,27.1\}$ \\
\hline \multirow[t]{10}{*}{4} & 4_1 & $\{a b c, d, e, f\}$ & $\{20.4,22.7,24.5,29.0\}$ \\
\hline & 4_2 & $\{a, b c d, e, f\}$ & $\{17.8,20.7,24.5,29.0\}$ \\
\hline & 4_3 & $\{a, b, c d e, f\}$ & $\{17.8,20.2,22.8,29.0\}$ \\
\hline & 4_4 & $\{a, b, c, d e f\}$ & $\{17.8,20.2,22.0,26.0\}$ \\
\hline & 4_5 & $\{a b, c d, e, f\}$ & $\{19.9,22.2,24.5,29.0\}$ \\
\hline & 4_6 & $\{a b, c, d e, f\}$ & $\{19.9,22.0,23.7,29.0\}$ \\
\hline & 4_7 & $\{a b, c, d, e f\}$ & $\{19.9,22.0,22.7,27.1\}$ \\
\hline & 4_8 & $\{a, b c, d e, f\}$ & $\{17.8,20.6,23.7,29.0\}$ \\
\hline & 4_9 & $\{a, b c, d, e f\}$ & $\{17.8,20.6,22.7,27.1\}$ \\
\hline & 4_10 & $\{a, b, c d, e f\}$ & $\{17.8,20.2,22.2,27.1\}$ \\
\hline \multirow[t]{10}{*}{3} & 3_1 & $\{a b c d, e, f\}$ & $\{20.5,24.5,29.0\}$ \\
\hline & $3 \_2$ & $\{a, b c d e, f\}$ & $\{17.8,21.1,29.0\}$ \\
\hline & 3_3 & $\{a, b, c d e f\}$ & $\{17.8,20.2,24.3\}$ \\
\hline & $3 \_4$ & $\{a b c, d e, f\}$ & $\{20.4,23.7,29.0\}$ \\
\hline & $3 \_5$ & $\{a b c, d, e f\}$ & $\{20.4,22.7,27.1\}$ \\
\hline & $3 \_6$ & $\{a, b c d, e f\}$ & $\{17.8,20.7,27.1\}$ \\
\hline & 3_7 & $\{a b, c d e, f\}$ & $\{19.9,22.8,29.0\}$ \\
\hline & 3_8 & $\{a, b c, d e f\}$ & $\{17.8,20.6,26.0\}$ \\
\hline & 3_9 & $\{a b, c, d e f\}$ & $\{19.9,22.0,26.0\}$ \\
\hline & 3_10 & $\{a b, c d, e f\}$ & $\{19.9,22.2,27.1\}$ \\
\hline
\end{tabular}


Table 2 Continued

\begin{tabular}{|c|c|c|c|}
\hline Group count & Scenario & Group & Average treatment time (minutes) \\
\hline \multirow[t]{5}{*}{2} & 2_1 & $\{a, b c d e f\}$ & $\{17.8,21.9\}$ \\
\hline & $2 \_2$ & $\{a b, c d e f\}$ & $\{19.9,24.3\}$ \\
\hline & 2_3 & $\{a b c, d e f\}$ & $\{20.4,26.0\}$ \\
\hline & 244 & $\{a b c d, e f\}$ & $\{20.5,27.1\}$ \\
\hline & $2 \_5$ & $\{a b c d e, f\}$ & $\{20.8,29.0\}$ \\
\hline 1 & all together & $\{a b c d e f\}$ & $\{21.6\}$ \\
\hline
\end{tabular}

\begin{tabular}{|l|l|l|l|}
\hline Slot & Morning & Slot & Afternoon \\
\hline 1 & OV & 12 & OV \\
\hline 2 & WCC & 13 & WCC \\
\hline 3 & OV & 14 & OV \\
\hline 4 & FU & 15 & FU \\
\hline 5 & OV & 16 & OV \\
\hline 6 & NP & 17 & NP \\
\hline 7 & OV & 18 & OV \\
\hline 8 & FU & 19 & ER/UC \\
\hline 9 & OV & 20 & OV \\
\hline 10 & PE & 21 & PE \\
\hline 11 & OV & 22 & OV \\
\hline
\end{tabular}

Table 3 The 22-patient Appointment Template

Table 4 Three Different Level of Patient Type Distribution

\begin{tabular}{|l|l|l|l|}
\hline Patient Slots & Level $\mathbf{1}$ & Level 2 & Level 3 \\
\hline 1 & OV & OV & OV \\
\hline 2 & WCC & WCC & WCC \\
\hline 3 & OV & OV & OV \\
\hline 4 & FU & NP & FU \\
\hline 5 & OV & OV & OV \\
\hline 6 & NP & FU & NP \\
\hline 7 & OV & OV & OV \\
\hline 8 & FU & NP & FU \\
\hline 9 & OV & OV & PE \\
\hline 10 & PE & PE & OV \\
\hline 11 & OV & OV & NP \\
\hline
\end{tabular}

\begin{tabular}{|l|l|l|l|}
\hline $\begin{array}{l}\text { Patient Slots } \\
\text { Lunch Break }\end{array}$ & Level 1 & Level 2 & Level 3 \\
\hline 12 & OV & OV & OV \\
\hline 13 & WCC & WCC & WCC \\
\hline 14 & OV & OV & OV \\
\hline 15 & FU & FU & FU \\
\hline 16 & OV & OV & OV \\
\hline 17 & NP & NP & PE \\
\hline 18 & OV & FU & OV \\
\hline 19 & ER/UC & ER/UC & ER/UC \\
\hline 20 & OV & OV & NP \\
\hline 21 & PE & PE & OV \\
\hline 22 & OV & OV & PE \\
\hline
\end{tabular}


Table 5 The Optimal Grouping on Changing Cost Ratio, No-show Rate, and Patient Type Distribution

\begin{tabular}{|c|c|c|c|c|c|c|}
\hline $\begin{array}{l}\text { Dis- } \\
\text { tribu- } \\
\text { tion }\end{array}$ & $\begin{array}{l}\text { No- } \\
\text { Show } \\
\text { Rate }\end{array}$ & $\begin{array}{l}\text { Cost } \\
\text { Ratio }\end{array}$ & $\begin{array}{l}\text { Optimal Scheduling } \\
\text { Group and Time }\end{array}$ & $\begin{array}{l}\text { Total- } \\
\text { Cost }\end{array}$ & $\begin{array}{l}\text { Clinic } \\
\text { Flow } \\
\text { Cost }\end{array}$ & $\begin{array}{l}\text { Appointment } \\
\text { Flexibility } \\
\text { Cost }\end{array}$ \\
\hline \multirow[t]{9}{*}{1} & \multirow[t]{3}{*}{$5.4 \%$} & 5 & 2_1 $\{a, b c d e f\}\{17.8,21.9\}$ & 93.05 & 89.60 & 3.44 \\
\hline & & 10 & 3_6 $\{a, b c d$, ef $\{17.8,20.7,27.1\}$ & 144.62 & 136.75 & 7.87 \\
\hline & & 15 & 3_6 $\{a, b c d$, ef $\{17.8,20.7,27.1\}$ & 195.03 & 187.16 & 7.87 \\
\hline & \multirow[t]{3}{*}{$10.4 \%$} & 5 & 2_1 $\{a, b c d e f\}\{17.8,21.9\}$ & 95.53 & 92.09 & 3.44 \\
\hline & & 10 & 3_6 $\{a, b c d$, ef $\{17.8,20.7,27.1\}$ & 155.54 & 147.68 & 7.87 \\
\hline & & 15 & 3_6 $\{a, b c d$, ef $\{17.8,20.7,27.1\}$ & 213.93 & 206.06 & 7.87 \\
\hline & \multirow[t]{3}{*}{$15.4 \%$} & 5 & 2_1 $\{a, b c d e f\}\{17.8,21.9\}$ & 104.94 & 101.50 & 3.44 \\
\hline & & 10 & 2_1 $\{a, b c d e f\}\{17.8,21.9\}$ & 179.38 & 175.94 & 3.44 \\
\hline & & 15 & 3_6 $\{a, b c d$, ef $\{17.8,20.7,27.1\}$ & 252.23 & 244.37 & 7.87 \\
\hline \multirow[t]{9}{*}{2} & \multirow[t]{3}{*}{$5.4 \%$} & 5 & 2_4 $\{a b c d, e f\}\{20.5,27.1\}$ & 97.23 & 91.34 & 5.89 \\
\hline & & 10 & 3_6 $\{a, b c d$, ef $\{17.8,20.7,27.1\}$ & 150.04 & 141.81 & 8.23 \\
\hline & & 15 & 3_6 $\{a, b c d$, ef $\{117.8,20.7,27.1\}$ & 202.69 & 194.46 & 8.23 \\
\hline & \multirow[t]{3}{*}{$10.4 \%$} & 5 & 2_4 $\{a b c d, e f\}\{20.5,27.1\}$ & 99.70 & 93.81 & 5.89 \\
\hline & & 10 & 3_6 $\{a, b c d$, ef $\{117.8,20.7,27.1\}$ & 160.24 & 152.02 & 8.23 \\
\hline & & 15 & 3_6 $\{a, b c d$, ef $\{17.8,20.7,27.1\}$ & 220.50 & 212.28 & 8.23 \\
\hline & \multirow[t]{3}{*}{$15.4 \%$} & 5 & 2_1 $\{a, b c d e f\}\{17.8,21.9\}$ & 109.84 & 106.16 & 3.68 \\
\hline & & 10 & 3_6 $\{a, b c d$, ef $\{17.8,20.7,27.1\}$ & 185.24 & 177.01 & 8.23 \\
\hline & & 15 & 3_6 $\{a, b c d$, ef $\{117.8,20.7,27.1\}$ & 260.13 & 251.90 & 8.23 \\
\hline \multirow[t]{9}{*}{3} & \multirow[t]{3}{*}{$5.4 \%$} & 5 & 2_5 $\{a b c d e, f\}\{20.8,29.0\}$ & 99.61 & 94.75 & 4.86 \\
\hline & & 10 & $4 \_2\{a, b c d, e, f\}\{17.8,20.7,24.5,29.0\}$ & 156.88 & 146.76 & 10.13 \\
\hline & & 15 & $4 \_2\{a, b c d, e, f\}\{17.8,20.7,24.5,29.0\}$ & 212.73 & 202.60 & 10.13 \\
\hline & \multirow[t]{3}{*}{$10.4 \%$} & 5 & 2_5 $\{a b c d e, f\}\{20.8,29.0\}$ & 101.48 & 96.62 & 4.86 \\
\hline & & 10 & 3_1 $\{a b c d, e, f\}\{20.5,24.5,29.0\}$ & 166.24 & 158.65 & 7.58 \\
\hline & & 15 & $4 \_2\{a, b c d, e, f\}\{17.8,20.7,24.5,29.0\}$ & 229.67 & 219.54 & 10.13 \\
\hline & \multirow[t]{3}{*}{$15.4 \%$} & 5 & 2_5 $\{a b c d e, f\}\{20.8,29.0\}$ & 111.22 & 106.36 & 4.86 \\
\hline & & 10 & 3_1 $\{a b c d, e, f\}\{20.5,24.5,29.0\}$ & 189.92 & 182.33 & 7.58 \\
\hline & & 15 & 3_1 $\{a b c d, e, f\}\{20.5,24.5,29.0\}$ & 268.09 & 260.51 & 7.58 \\
\hline
\end{tabular}




\section{References}

1. Lian J, Distefano K, Shields SD, Heinichen C, Giampietri M, Wang L. Clinical appointment process: improvement through schedule defragmentation. IEEE Eng Med Biol Mag 2010; 29(2): 127-134.

2. Huang Y, Zuniga P. Dynamic overbooking scheduling system to improve patient access. J Oper Res Soc 2012; 63(6): 810-820.

3. Keehl-Markowitz L, Ayanian JZ, Mehrotra A. Implementing Open-Access Scheduling of Visits in Primary Care Practices: A Cautionary Tale. Ann Intern Med 2008; 148(12): 915-922.

4. Vanden Bosch PM, Dietz DC. Minimizing expected waiting in a medical appointment system. IIE Trans 2000; 32(9): 841-848.

5. Huang Y. Ancillary service impact on outpatient scheduling. Int J Health Care Qual Assur 2013; 26(8): 746-759.

6. Millhiser WP, Veral EA. Designing appointment system templates with operational performance targets. IIE Trans Healthc Syst Eng 2015; 5(3): 125-146.

7. LaGanga LR, Lawrence SR. Clinic Overbooking to Improve Patient Access and Increase Provider Productivity. Dec Sci 2007; 38(2): 251-276.

8. Huang Y, Hancock WM, Herrin GD. An alternative outpatient scheduling system: Improving the outpatient experience. IIE Trans Healthc Syst Eng 2012; 2(2): 97-111.

9. Swisher JR, Jacobson SH, Jun JB, Balci O. Modeling and Analyzing a Physician Clinic Environment Using Discrete-Event (Visual) Simulation. Comput Oper Res 2001; 28(2): 105-125.

10. Sweeney DR. Your office: a lot of things will have to change. Med Econ 1996; 73(7): 97-106.

11. Blumenthal D. Performance improvement in health care - seizing the moment. N Eng J Med 2012; 366(21): 1953-1955.

12. Tai G, Williams P. Optimization of scheduling patient appointments in clinics using a novel modeling technique of patient arrival. Comput Meth Prog Bio 2011; 108(2): 467-476.

13. Klassen KJ, Yoogalingam R. Appointment system design with interruptions and physician lateness. Int J Oper Prod Man 2013; 33(4): 394-414.

14.Zeng B, Zhao H, Lawley M. The impact of overbooking on primary care patient no-show. IIE Trans Healthc Syst Eng 2013; 3(3): 147-170.

15. Vanden Bosch PM, Dietz DC. Minimizing expected waiting in a medical appointment system. IIE Trans 2000; 32(9): 841-848.

16. Harper PR, Gamlin HM. Reduced outpatient waiting times with improved appointment scheduling: a simulation modeling approach. OR Spectrum 2003; 25(2): 207-222.

17. Cayirli T, Veral E, Rosen H. Assessment of Patient Classification in Appointment System Design. Prod Oper Manag 2008; 17(3): 338-353.

18. Tang J, Yan C, Cao P. Appointment scheduling algorithm considering routine and urgent patients. Expert Syst Appl 2014; 41(10): 4529-4541.

19. Huang Y, Zuniga P, Marcak J. A cost-effective urgent care policy to improve patient access in a dynamic scheduled clinic setting. J Oper Res Soc 2014; 65(5): 763-776.

20. Cayirli T, Yang KK, Quek SA. A Universal Appointment Rule in the Presence of No-Shows and Walk-Ins. Prod Oper Manag 2012; 21(4): 682-697.

21. OH H, Muriel A, Balasubramanian H, Atkinson K, Ptaszkiewicz T. Guidelines for scheduling in primary care under different patient types and stochastic nurse and provider service times. IIE Trans Healthc Syst Eng 2013; 3(4): 263-279.

22.Kuiper A, Kemper B, Mandjes M. A Computational approach to optimized appointment scheduling. Queueing Systems 2015; 79(1): 5-36.

23.LaGanga LR, Lawrence SR. Appointment Overbooking in Health care Clinics to Improve Patient Service and Clinic Performance. Prod Oper Manag 2012; 21(5): 874-888.

24.Zacharias C, Pinedo M. Appointment Scheduling with No-Shows and Overbooking. Prod Oper Manag 2014; 23(5): 788-801.

25. Tsai PJ, Teng G. A stochastic appointment scheduling system on multiple resources with dynamic call-in sequence and patient no-shows for an outpatient clinic. Eur J Oper Res 2014; 239(2): 427-436.

26. Huang Y, Hanauer DA. Patient No-Show Predictive Model Development using Multiple Data Sources for an Effective Overbooking Approach. Appl Clin Inform 2014; 5(3): 836-860.

27. Samorani M, LaGanga LR. Outpatient appointment scheduling given individual day-dependent no-show predictions. Eur J Oper Res 2015; 240(1): 245-257.

28. Lin J, Muthuraman K, Lawley M. Optimal and approximate algorithms for sequential clinical scheduling with no-shows. IIE Trans Healthc Syst Eng 2011; 1(1): 20-36. 
29. Berg BP, Denton BT, Erdogan SA, Rohleder T, Huschka T. Optimal booking and scheduling in outpatient procedure centers. Comput Oper Res 2014; 50: 24-37.

30.Huang Y, Marcak J. Grid Patient Appointment Template Design to Improve Scheduling Effectiveness. J Healthc Eng 2015; 6(2): 239-258.

31. Huang Y, Kammerdiner A. Reduction of service time variation in patient visit groups using decision tree method for an effective scheduling. Int. J. of Healthcare Technology and Management 2013; 14(1/2): 3-21.

32. Huang Y, Verduzco S. Appointment Template Redesign in a Women's Health Clinic Using Clinical Constraints to Improve Service Quality and Efficiency. Appl Clin Inform 2015; 6(2): 271-287.

33. Huang Y, Marcak J. Radiology scheduling with consideration of patient characteristics to improve patient access to care and medical resource utilization. Health Systems 2013; 2(2): 93-102.

34. Wijewickrama A, Takakuwa S. Designing Outpatient Appointment Systems with Patient Characteristics: a Case Study. Int. J. of Healthcare Technology and Management 2012; 13(1/2/3): 157-69.

35. Carson Y, Maria A. Simulation Optimization: Methods and Applications. Proceedings of the 1997 Winter Simulation Conference.

36. Yang KK, Lau ML, Quek SA. A New Appointment Rule for a Single-Server, Multiple-Customer Service System. Nav Res Log 1998; 45(3): 313-326.

37. Cayirli T, and Veral E. Outpatient Scheduling in Health Care: A Review of Literature. Prod Oper Manag 2003; 12(4): 519-549.

38. Kros J, Dellana S, West D. Overbooking Increases Patient Access at East Carolina University's Student Health Services Clinic. Interfaces 2009; 39(3): 271-287. 